\title{
Osteogenesis Imperfecta with Celiac Disease and Type II Diabetes Mellitus Associated: Improvement with a Gluten-Free Diet
}

\author{
Luis Rodrigo and Isabel Pérez-Martinez \\ Gastroenterology Service, Hospital Universitario Central de Asturias (HUCA), University of Oviedo, \\ c/Celestino Villamil s. no. 33006, Oviedo, Spain \\ Correspondence should be addressed to Luis Rodrigo, lrodrigosaez@gmail.com
}

Received 13 December 2011; Accepted 26 December 2011

Academic Editor: Edward V. Craig

Copyright ( 2012 L. Rodrigo and I. Pérez-Martinez. This is an open access article distributed under the Creative Commons Attribution License, which permits unrestricted use, distribution, and reproduction in any medium, provided the original work is properly cited.

\begin{abstract}
Osteogenesis imperfecta (OI) is a genetic disease, with a connective tissue alteration, consisting in the presence of multiple spontaneous fractures or after minimal traumatism. Its association with other metabolic processes is rarely described. We present the clinical case of a female adult patient of 43 years. From her infancy, she has had multiple fractures, needing several surgical interventions, and she was diagnosed of OI type 2 at adolescence age. Due mainly to difficulties in walking remaining in wheelchair in the last three years, she was overweight with morbid obesity (BMI $=45.4)$ and had a type-II DM associated. She suffered from recurrent abdominal pain and chronic diarrhea and was diagnosed of celiac disease (CD) with increased intraepithelial duodenal infiltration, being classified as lymphocytic enteritis, Marsh I type. She was put on a gluten-free diet (GFD), having lost $6 \mathrm{~kg}$ of weight after 6 months, with a good control of DM-II and presenting a significant clinical improvement. It is rewarding to search the presence of two coincidental metabolic diseases associated to OI, specially CD, because of the dramatic clinical benefit in the general found after putting on a GFD.
\end{abstract}

\section{Introduction}

Osteogenesis imperfecta (OI) is a genetic disease, associated with a connective tissue disorder, related to different phenotypic presentations. It is also called "brittle bone disease." Severely affected patients have multiple fractures since childhood, both spontaneous or related to minimal trauma, and the most seriously affected children usually die in the neonatal period. Milder forms of OI may be manifested later on, in the form of early osteoporosis or bone mineral loss, that is more important after the menopause $[1,2]$.

Its association with other metabolic processes is rarely described. We present here the case of an adult woman with a severe OI, diagnosed in the adolescence period and more recently of celiac disease (CD) and type II diabetes mellitus (DM-II), describing its evolution and changes after starting on a gluten-free diet (GFD).

\section{Case Presentation}

We present the case of a 43-year-old female. Shortly after birth, she presented a spontaneous right hip fracture. From then, until now, she has had multiple fractures of both arms and legs, which have required several interventions for correction, needing on the left humerus to be fixed with a medullary locking (Figure 1). The last fracture episode happened 3 years ago. OI type 2 was diagnosed, 20 years ago. For moving at home, she walks with difficulty with a cane, and, on the street, she is moved by wheelchair. She presents a significant growth delay $\left(\mathrm{High}=1^{\prime} 14 \mathrm{~m}\right)$ and weighed $65 \mathrm{~kg}$, presenting a picture of morbid obesity, with an increased body mass index $\left(\mathrm{BMI}=45.4 \mathrm{~kg} / \mathrm{m}^{2}\right)$.

She relates that for about 2 years, and she has slow digestion, accompanied by marked abdominal bloating, accompanied by heartburn and reflux. The major alteration in her bowel habit was an alternating pattern with diarrhea 


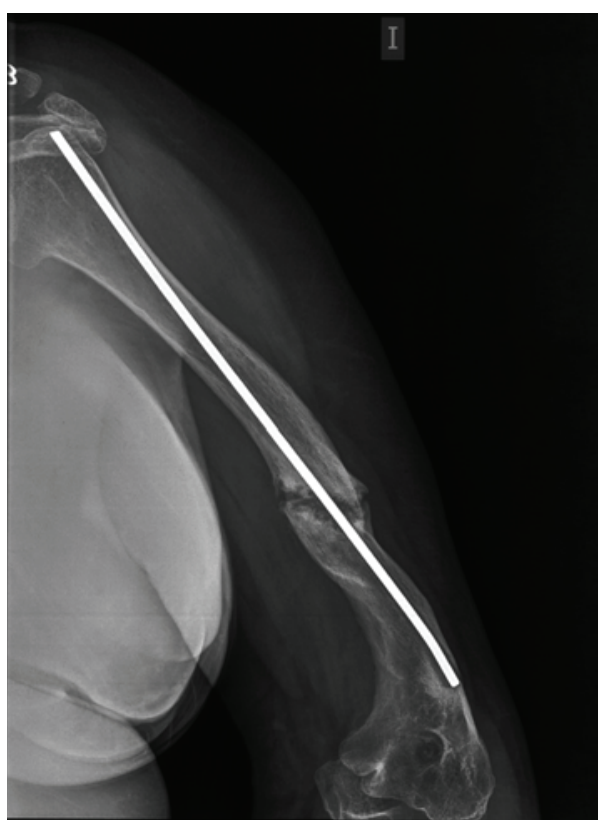

FIgURE 1: Intramedullary nail placed on the left humerus fracture.

and constipation. The patient had also bilateral hearing loss, requiring hearing aids for ten years.

Currently, the CBC was normal. Blood glucose was elevated $(230 \mathrm{mg} / \mathrm{dL})$ with increased glucosuria $(4+)$. The rest of biochemical analysis was normal. She underwent a gastroscopy that showed a moderate reflux oesophagitis (grade B Angeles classification) without associated hiatal hernia. Duodenal biopsies showed an increased intraepithelial lymphocytosis (45\%) corresponding to stage I of affordable Marsh. Genetic markers of CD type DQ2 were positive in homozygosis, and antibodies to tissue transglutaminase (tTG) were normal $(0.6 \mathrm{U} / \mathrm{mL})$. Antinuclear antibodies were negative. Vitamin D deficiency was excluded.

\section{Intervention}

She was started on a gluten-free diet (GFD) and an oral antibiotic drug, type Metformine- $850 \mathrm{mg} /$ twice daily was given, having lost $6 \mathrm{~kg}$ of weight in 6 months with good control of DM-II and presenting a significantly improvement related to the presence of prior digestive problem. A recently completed study of bone mineral density (BMD) has been reported as normal.

\section{Discussion}

The estimated incidence of OI is approximately one case per live 20,000 births. This means that it is included within the so-called orphan diseases as defined in the USA when the disease affects fewer than 200,000 people. There are over 200 genetic mutations associated with the phenotype of OI [3].

Most OI patients have mutations that affect one or both chains of type I collagen, although up to $10 \%$ of patients do not have them. The defect in bone quality explains many of the clinical aspects of OI.
The most common clinical manifestations include the presence of multiple fractures, associated by short stature, scoliosis, deformities of the skull base, blue sclerae, hearing loss, opalescent teeth, increased laxity of ligaments and skin, and presence of spontaneous bruising. The frequency of fractures decreases after the puberty [4-6]. The diagnosis of OI is based on signs and symptoms listed above. A positive family history is a factor of great help. However, in the absence of these events, it can be difficult to achieve. Extraskeletal manifestations may be subclinical (deafness, blue sclerae, or defective dentinogenesis).

Although the biochemical parameters are normal, some alterations may be present, such as high levels of alkaline phosphatase; the presence of hypercalciuria is common in children, together with increased bone resorption markers $[7,8]$. Their association in adults with CD and DMII is poorly understood, but its diagnosis and treatment significantly improve the quality of life of patients and therefore to her clinical and/or analytical, it is advisable to perform an adequate search of these diseases, for their early identification and treatment $[9,10]$.

In conclusion, we must emphasize the convenience of ruling out the presence of a gluten intolerance in patients with osteogenesis imperfecta, mainly if they present a type II diabetes mellitus associated, and the clear clinical benefit observed on a GFD, as it has been shown in the presented case.

\section{References}

[1] F. Rauch and F. H. Glorieux, "Osteogenesis imperfecta," Lancet, vol. 363, no. 9418, pp. 1377-1385, 2004.

[2] R. Smith, "Idiopathic juvenile osteoporosis: experience of twenty-one patients," British Journal of Rheumatology, vol. 34, no. 1, pp. 68-77, 1995.

[3] H. Plotkin, "Syndromes with congenital brittle bones," BMC Pediatrics, vol. 4, article no. 16, 2004.

[4] F. Antoniazzi, M. Mottes, P. Fraschini, P. C. Brunelli, and L. Tatò, "Osteogenesis imperfecta: practical treatment guidelines," Paediatric Drugs, vol. 2, no. 6, pp. 465-488, 2000.

[5] "Osteogenesis imperfecta," in Preventive management of children wih congenital anomalies and syndromes, Wilson G. N. and Cooley W. C., Eds., p. 256, Cambridge University Press, Cambridge, UK, 2000.

[6] C. R. Paterson, E. A. Monk, and S. J. McAllion, "How common is hearing impairment in osteogenesis imperfecta?" Journal of Laryngology and Otology, vol. 115, no. 4, pp. 280-282, 2001.

[7] A. Chines, A. Boniface, W. Mcalister, and M. Whyte, "Hypercalciuria in osteogenesis imperfecta: a follow-up study to assess renal effects," Bone, vol. 16, no. 3, pp. 333-339, 1995.

[8] A. M. Lund, M. Hansen, G. Kollerup, A. Juul, B. Teisner, and F. Skovby, "Collagen-derived markers of bone metabolism in osteogenesis imperfecta," Acta Paediatrica, International Journal of Paediatrics, vol. 87, no. 11, pp. 1131-1137, 1998.

[9] J. F. Ludvigsson, K. Michaelsson, A. Ekbom, and S. M. Montgomery, "Coeliac disease and the risk of fractures-a general population-based cohort study," Alimentary Pharmacology and Therapeutics, vol. 25, no. 3, pp. 273-285, 2007.

[10] M. R. Jafri, C. W. Nordstrom, J. A. Murray et al., "Long-term fracture risk in patients with celiac disease: a population-based study in Olmsted County, Minnesota," Digestive Diseases and Sciences, vol. 53, no. 4, pp. 964-971, 2008. 


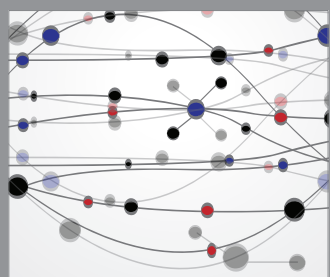

The Scientific World Journal
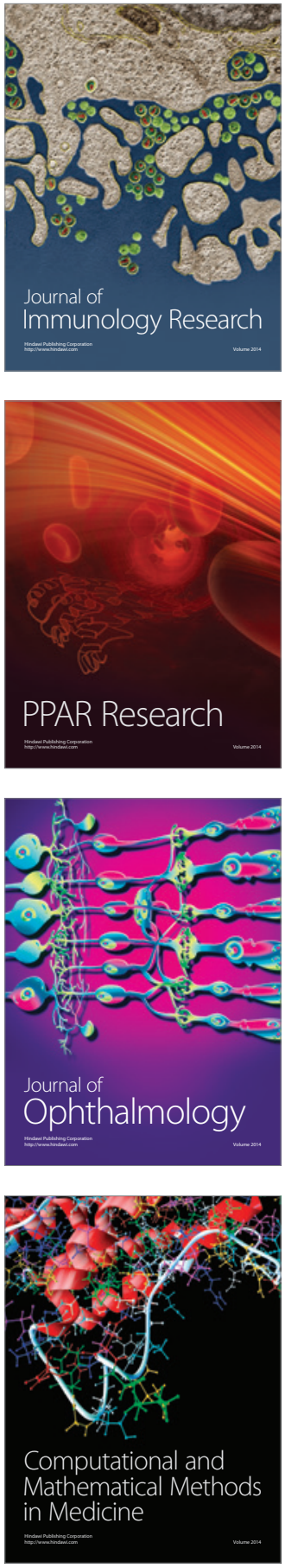

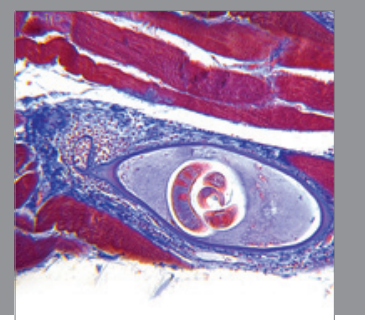

Gastroenterology

Research and Practice
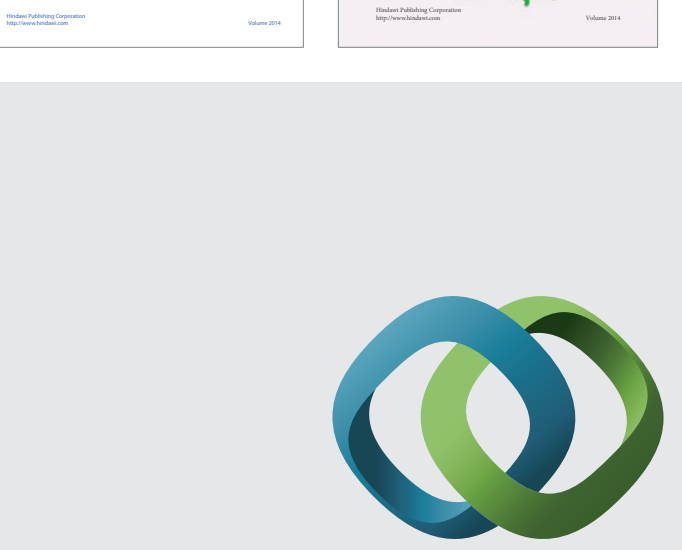

\section{Hindawi}

Submit your manuscripts at

http://www.hindawi.com
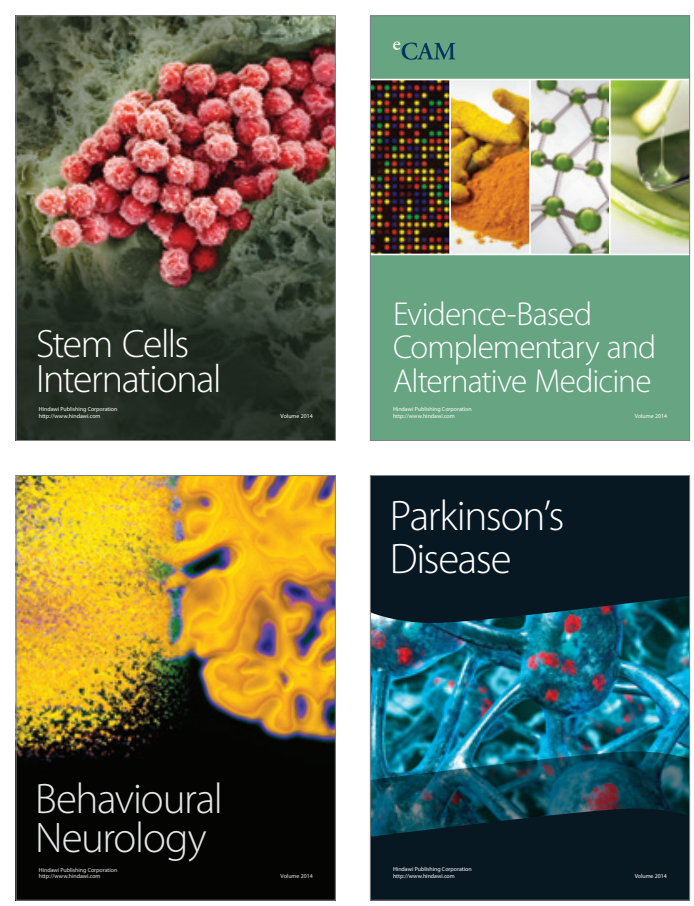

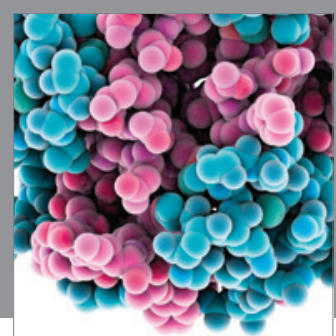

Journal of
Diabetes Research

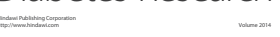

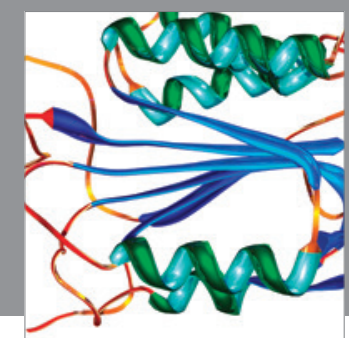

Disease Markers
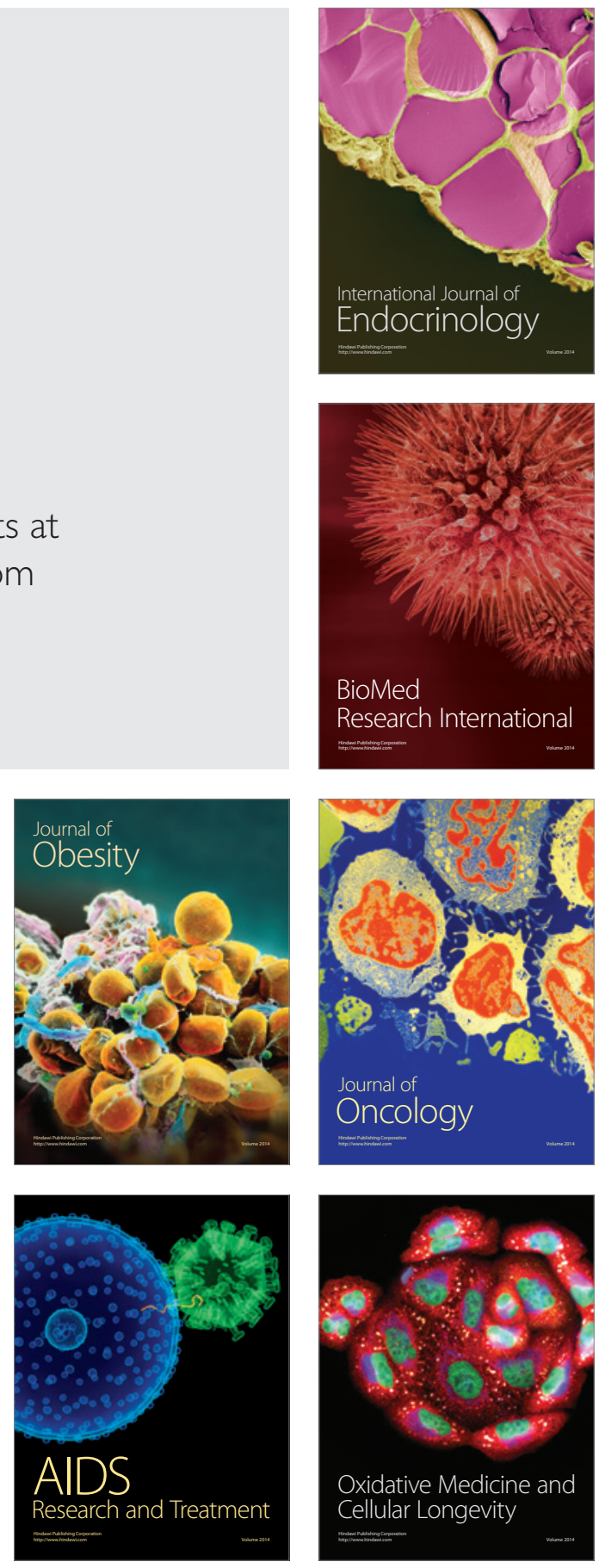